\title{
Restarted State Parameterization Method for Optimal Control Problems
}

\author{
B. Kafash ${ }^{1,2, *}$, A. Delavarkhalafi ${ }^{1}$ \\ ${ }^{1}$ Imam Javad University College, Yazd, Iran \\ ${ }^{2}$ Department of Mathematics, Yazd University, Yazd, Iran \\ *Bkafash@gmail.com
}

Article history:

Received July 2014

Accepted August 2014

Available online November 2014

Abstract
In this paper we introduce an efficient algorithm based on state parameterization method to solve optimal control problems and Van Der Pol oscillator. In fact, state variable can be considered as linear combination of polynomials with unknown coefficients. Using this method, an optimal control problem breaks down into an optimization and will be solved via mathematical programming techniques. By this algorithm, the control and state variables can be approximated as a function of time. Finally, some numerical examples are presented to show the validity and efficiency of the proposed method.

Keywords: Optimal control problems, State parameterization method, Mathematical programming techniques, Van Der Pol oscillator.

\section{Introduction}

Optimal control theory, an extension of the calculus of variations, is a mathematical optimization method for deriving control policies. The method is largely due to the work of Lev Pontryagin and his collaborators in the Soviet Union [1] and Richard Bellman in the United States [2]. In general, optimal control is divided into two major parts, namely deterministic and stochastic control. In deterministic setting, there are many text books for analytic solutions of optimal control problems such as [1-7]. Also, numerical methods for these problems have been provided in [8-13]. The stochastic optimal control problem has been studied in textbooks and studied by many researchers (for example see [3], [4], [8] and [9]). In general, an optimal control problem can be solved by one of the following methods [14]:

1- Bellman's dynamic programming method which is based on the principle of optimality (HamiltonJacobi-Bellman equation).

2- Pontryagin's minimum principle and calculus of variations (Euler-Lagrange equations).

3- Direct methods using parameterization or discretization (nonlinear mathematical programming).

As analytical solutions for problems of optimal control are not always available, thus finding an approximate solution is at least the most logical way to solve them. The study of numerical methods has provided an attractive field for researchers of mathematical sciences which have risen to the appearance of different numerical computational methods and efficient algorithms to solve the optimal control problems $[14,15]$. 
In [16], the distributed optimal control problem governed by unsteady diffusion-convection-reaction equation without control constraints is studied.

The authors in [17], considers a class of optimal control problems for general nonlinear time-delay systems with free terminal time.

Phelps et al. focuses on a non-standard constrained nonlinear optimal control problem in which the objective functional involves integration over a space of stochastic parameters as well as integration over the time domain [18]. In [19], for one-dimensional stochastic linear fractional systems the optimal control is derived and in [20] truncated Bessel series approximation by using collocation scheme, for solving linear and nonlinear fractional optimal control problems (OCPs) indirectly. In particular, the control parameterization technique is used in [21, 22] and control parameterization enhancing technique is introduced in [22, 23]. Vlassenbroec presented a numerical technique for solving non-linear constrained optimal control problems [24]. Van Dooren and Vlassenbroech [25] have introduced a direct method for the controlled Duffing oscillator. El-Gindy, et. al. [26] has presented an alternative technique for solving the controlled Duffing oscillator problems, which is based on El-Gendi method [26]. In [27], a numerical technique is presented for solving the controlled Duffing oscillator; in which the control and state variables are approximated by Chebyshev series. State parameterization converts the problem to a nonlinear optimization problem and finds unknown polynomial coefficients of degree at most $n$ in the form of $\mathrm{x}(\mathrm{t})=\sum_{\mathrm{i}=0}^{\mathrm{n}} \mathrm{a}_{\mathrm{i}} \mathrm{t}^{\mathrm{i}}$, for optimal solution [29,30]. In [15], an algorithm for solving optimal control problems and the controlled Duffing oscillator is presented; in the algorithm the solution is based on state parameterization such that the state variable can be considered as a linear combination of Chebyshev polynomials with unknown coefficients and later, extended state parameterization to solve nonlinear optimal control problems and the controlled Duffing oscillator [31]. The authors in [32], presented a computational method based on state parametrization of state variable by using Boubaker polynomials for solving optimal control problems and the controlled Duffing oscillator.

This paper is organized into following sections of which this introduction is the first. In Section 2, we introduce problem statement. Section 3 is about state parameterization. State parameterization method is described in Section 4. Section 5 derives the proposed design method, in fact restarted state parameterization method is described. In section 6 we present some numerical examples to illustrate the efficiency and reliability of the presented method. Also, The solution of Van Der Pol oscillator with the presented algorithm are presented in section 7. Finally, the paper is concluded with conclusion.

\section{Optimal control problems}

In describing a control model, the kind of information available to the controller at each instant of time plays an important role. In describing a control model two cases exist; either the controller has no information during the system operation, known as open loop, or the controller knows the state of the system at each instant of time $t$, known as feedback. In optimal control problem, we have to determine one of these presented controls. The control function $\mathrm{u}$ is assumed to be piecewise from a class of admissible controls $\mathrm{U}$. Each choice of control $\mathrm{u}(\mathrm{t}) \in \mathbb{R}^{\mathrm{m}}$ yields a process $\mathrm{x}(\mathrm{t}) \in \mathbb{R}^{\mathrm{n}}$ which is the unique solution of

$$
\dot{\mathrm{x}}(\mathrm{t})=\mathrm{f}(\mathrm{t}, \mathrm{x}(\mathrm{t}), \mathrm{u}(\mathrm{t}))
$$

which is called the equation of motion, on a fixed interval $\left[\mathrm{t}_{0}, \mathrm{t}_{1}\right]$ with initial condition

$$
x\left(t_{0}\right)=x_{0}
$$

Along with this controlled process, a cost functional of the form:

$$
\mathcal{J}=\phi\left(x\left(\mathrm{t}_{0}\right), \mathrm{t}_{0}, \mathrm{x}\left(\mathrm{t}_{1}\right), \mathrm{t}_{1}\right)+\int_{\mathrm{t}_{0}}^{\mathrm{t}_{1}} \mathrm{~L}(\mathrm{t}, \mathrm{x}(\mathrm{t}), \mathrm{u}(\mathrm{t})) \mathrm{dt},
$$

Is defined. Here, $\mathrm{L}$ is the running cost, and $\phi$ is the terminal cost. This cost functional depends on the initial position $\left(t_{0}, x_{0}\right)$ and the choice of control $u($.$) . The optimization problem is therefore to minimize \mathcal{J}$, for 
each $\left(\mathrm{x}_{0}, \mathrm{u}\right)$, over all controls $\mathrm{u}(\mathrm{t}) \in \mathrm{U}$. The optimization problem with performance index as defined in Equation (3) is called a Bolza problem. There are two other equivalent optimization problems, which are called Lagrange and Mayer problems [3].

\section{State parameterization}

The optimal control problems can be converted into a mathematical programming problem by using the parameterization techniques. One such technique is known as state parameterization. The idea of state parameterization is to approximate only the system state variable by a sequence of given functions with unknown parameters, which can be employed using different basis functions:

$$
x(t)=\sum_{i=0}^{n} a_{i} \Phi_{i}(t),
$$

and then the control variable are obtained from the state equations. The state parameterization can be employed using different basis functions. Let $\mathrm{Q} \subset \mathrm{C}^{1}\left(\left[\mathrm{t}_{0}, \mathrm{t}_{1}\right]\right)$ consisting of all functions passing through $\left(\mathrm{t}_{0}, \mathrm{x}_{0}\right)$. As, the performance index $\mathrm{J}(\mathrm{x}()$.$) may be considered as a function of \mathrm{x}($.$) . Then the optimal control problem may be$ interpreted as minimization of $J$ on the set $Q$. Let $Q_{n}$ be a sub set of $Q$ consisting of all polynomials of degree at most $n$ as Equation (4). Now consider the minimization of $J$ on $Q_{n}$ with $\left\{a_{k}\right\}_{k=0}^{n}$ as unknowns. This is an optimization problem in $(n+1)$-dimensional space and $J\left(x_{n}().\right)$ may be considered as $J\left(a_{0}, a_{1}, \ldots, a_{n}\right)$.

\section{Restarted State Parameterization Method}

In this section, Restarted State Parameterization Method by using polynomials bases is introduced. This method is a numerical method for solving optimal control problems. In fact, we can accurately represent state and control functions with only a few parameters. First, from Equation (1), the expression for $u(t)$ as a function of $t, x(t)$ and $\dot{\mathrm{x}}(\mathrm{t})$ is determined, i.e. [32]:

$$
u(t)=g(t, x(t), \dot{x}(t))
$$

First, state variable is approximated as follow:

$$
\mathrm{x}_{1}\left(\mathrm{t}, \mathrm{a}_{0}, \mathrm{a}_{1}, \mathrm{a}_{2}\right)=\sum_{\mathrm{i}=0}^{2} \mathrm{a}_{\mathrm{i}} \mathrm{t}^{\mathrm{i}}
$$

The control variables are determined from the system state equations (5) as a function of the unknown parameters of the state variables:

$$
\mathrm{u}_{1}\left(\mathrm{t}, \mathrm{a}_{0}, \mathrm{a}_{1}, \mathrm{a}_{2}\right)=\mathrm{g}\left(\mathrm{t}, \sum_{\mathrm{i}=0}^{2} \mathrm{a}_{\mathrm{i}} \mathrm{t}^{\mathrm{i}}, \sum_{\mathrm{i}=1}^{2} \mathrm{ia}_{\mathrm{i}} \mathrm{t}^{\mathrm{i}-1}\right)
$$

By substituting these approximations of the above state and control variables into the performance index (3) obtained:

$$
J\left(a_{0}, a_{1}, a_{2}\right)=\phi\left(a_{0}, a_{1}, a_{2}\right)+\int_{t_{0}}^{t_{1}} L\left(t, x_{1}\left(t, a_{0}, a_{1}, a_{2}\right), u_{1}\left(t, a_{0}, a_{1}, a_{2}\right)\right) d t
$$

The initial condition is replaced by equality constraint as follow, which is a linear constrain:

$$
\mathrm{x}\left(\mathrm{t}_{0}\right)=\mathrm{x}_{0} \Rightarrow \mathrm{x}_{1}\left(\mathrm{t}_{0}, \mathrm{a}_{0}, \mathrm{a}_{1}, \mathrm{a}_{2}\right)=\mathrm{x}_{0}
$$

Thus, the optimal control problem (1)-(3) converted into a quadratic function of the unknown parameters $\mathrm{a}_{0}, \mathrm{a}_{1}, \mathrm{a}_{2}$. In fact, the new problem can be stated as:

$$
\begin{aligned}
& \min _{\left(a_{0}, a_{1}, a_{2}\right) \in \mathbb{R}^{3}} J\left(a_{0}, a_{1}, a_{2}\right) \\
& \text { s. t. } x_{1}\left(t_{0}, a_{0}, a_{1}, a_{2}\right)=x_{0}
\end{aligned}
$$

Now, the control and state variables can be approximated as a function of time. In the next step, $x_{2}(t)$ is approximated as below for given $\mathrm{m}$ : 


$$
\mathrm{x}_{2}\left(\mathrm{t}, \mathrm{a}_{3}, \mathrm{a}_{4}, \ldots, \mathrm{a}_{\mathrm{m}}\right)=\mathrm{x}_{1}(\mathrm{t})+\sum_{\mathrm{i}=3}^{\mathrm{m}} \mathrm{a}_{\mathrm{i}} \mathrm{t}^{\mathrm{i}}
$$

and we obtain $\mathrm{J}$ as a function of $\mathrm{a}_{3}, \mathrm{a}_{4}, \ldots, \mathrm{a}_{\mathrm{m}}$ by using equation (3) and refer to it as $\hat{\mathrm{J}}$. If $\mathrm{a}^{*}$ be the value which minimizes $\widehat{J}$, then $\hat{J}\left(a^{*}\right)$ is the solution of optimal control problem in Equations (1)-(3). Also we can calculate state and control variables from $\mathrm{a}^{*}$ approximately.

By continuing this procedure we obtain a favorable accuracy, for example in the $(n+1)^{\text {th }}$ step, the approximate solution is given by:

$$
x_{n+1}(t)=x_{n}(t)+\sum_{j=i}^{i+m} a_{j} t^{j}
$$

and then $\mathrm{u}(\mathrm{t})$ can be obtained from equation (5). Now we obtain $\mathrm{J}$ as a function of $\mathrm{a}_{\mathrm{i}}, \mathrm{a}_{\mathrm{i}+1}, \ldots, \mathrm{a}_{\mathrm{i}+\mathrm{m}}$ by calculating $\mathcal{J}=\phi\left(x\left(\mathrm{t}_{0}\right), \mathrm{t}_{0}, \mathrm{x}\left(\mathrm{t}_{1}\right), \mathrm{t}_{1}\right)+\int_{\mathrm{t}_{0}}^{\mathrm{t}_{1}} \mathrm{~L}(\mathrm{t}, \mathrm{x}(\mathrm{t}), \mathrm{u}(\mathrm{t})) \mathrm{dt}$, and refer to it as $\hat{\jmath}$. The new problem can be stated as:

$$
\begin{aligned}
& \min _{\left(a_{i}, a_{i+1}, \ldots, a_{i+m}\right) \in \mathbb{R}^{m}} J\left(a_{i}, a_{i+1}, \ldots, a_{i+m}\right), \\
& \text { s.t. } x_{n+1}\left(t_{0}, a_{i}, a_{i+1}, \ldots, a_{i+m}\right)=x_{0},
\end{aligned}
$$

let $\mathrm{a}^{*}$ be the value which minimizes $\hat{\jmath}$, then $\hat{\mathrm{J}}\left(\mathrm{a}^{*}\right)$ is the solution of optimal control problem in equations (1)-(3). Also we can calculate state and control variables from $\mathrm{a}^{*}$ approximately.

The above results lead to the following algorithm which obtains the optimal performance index J(.).

\section{Presented algorithm:}

Input: Optimal control problem (1)-(3).

Output: The approximate optimal trajectory, approximate optimal control and approximate performance index J. Choose small positive number $\mathcal{E}$ and small natural number $\mathrm{m}$.

(Step 1)

Let $\mathrm{x}_{1}(\mathrm{t})=\sum_{\mathrm{i}=0}^{2} \mathrm{a}_{\mathrm{i}} \mathrm{t}^{\mathrm{i}}$ and $\alpha_{1}=\min _{\left(\mathrm{a}_{0}, \mathrm{a}_{1}, \mathrm{a}_{2}\right) \in \mathbb{R}^{3}} \mathrm{~J}\left(\mathrm{a}_{0}, \mathrm{a}_{1}, \mathrm{a}_{2}\right)$ subject to $\mathrm{x}_{1}\left(\mathrm{t}_{0}, \mathrm{a}_{0}, \mathrm{a}_{1}, \mathrm{a}_{2}\right)=\mathrm{x}_{0}$.

(Step 2)

For $\mathrm{i}=1,2, \ldots$ let $\mathrm{x}_{\mathrm{i}+1}(\mathrm{t})=\mathrm{x}_{\mathrm{i}}(\mathrm{t})+\sum_{\mathrm{j}=\mathrm{i}}^{\mathrm{i}+\mathrm{m}} \mathrm{a}_{\mathrm{j}} \mathrm{t}^{\mathrm{j}}$ and compute:

$$
\begin{aligned}
& \alpha_{i}=\underset{\left(a_{i}, a_{i+1}, \ldots, a_{i+m}\right) \in \mathbb{R}^{m}}{\min } J\left(a_{i}, a_{i+1}, \ldots, a_{i+m}\right), \\
& \text { s.t. } x_{n+1}\left(t_{0}, a_{i}, a_{i+1}, \ldots, a_{i+m}\right)=x_{0},
\end{aligned}
$$

If $\left|\alpha_{i+1}-\alpha_{i}\right|<E$ stop.

End (for).

As a well-known powerful tool, for convergence of the parameterization techniques we have the following theorem [33]:

Theorem 1 (Weierstrass Approximation Theorem). Let $\mathrm{f} \in \mathrm{C}([\mathrm{a}, \mathrm{b}], \mathbb{R})$. Then there is a sequence of polynomials $P_{n}(t)$ that converges uniformly to $f(x)$ on $[a, b]$.

Note: Theoretical treatment of the convergence of the parameterization technique is based on Weierstrass Approximation Theorem and has been considered in [11, 24-32].

Theorem 2 If $\alpha_{n}=\min _{Q_{n}} J$, for $n=1,2,3, \ldots$, then $\lim _{n \rightarrow \infty} \alpha_{n}=\alpha$ where $\alpha_{n}=\min _{Q} J$.

Proof. See [30-32]. 


\section{Numerical Results}

To illustrate the efficiency of the algorithms, we consider the following examples.

Example1. Consider the following test problem:

Minimize:

$$
\int_{0}^{1}\left(\frac{1}{2} u^{2}(t)+x^{2}(t)\right) d t
$$

Subject to:

$$
\dot{x}(t)=\frac{1}{2} x(t)+u(t), \quad x(0)=1 .
$$

With the optimal solution:

$$
x^{*}(t)=\frac{2 e^{3 t}+e^{3}}{2 e^{3 t / 2}\left(2+e^{3}\right)}, u^{*}(t)=\frac{2 e^{3 t}-e^{3}}{2 e^{3 t / 2}\left(2+e^{3}\right)}
$$

Also, the exact solution for the performance index is:

$J=\frac{e^{6}+e^{3}-2}{e^{6}+4 e^{3}+4}=0.8641644978$.

By using step (1) of the presented algorithm we consider this approximation of $x_{1}(t)$ to start with:

$$
\mathrm{x}_{1}\left(\mathrm{t}, \mathrm{a}_{0}, \mathrm{a}_{1}, \mathrm{a}_{2}\right)=\sum_{\mathrm{i}=0}^{2} \mathrm{a}_{\mathrm{i}} \mathrm{t}^{\mathrm{i}}
$$

from equation (7), we have:

$$
u_{1}\left(t, a_{0}, a_{1}, a_{2}\right)=-\frac{1}{2} a_{2} t^{2}+\left(2 a_{2}-\frac{1}{2} a_{1}\right) t+a_{1}-\frac{1}{2} a_{0},
$$

then substituting equations (8) and (9) into equation (6) gives:

$$
\mathrm{J}\left(\mathrm{a}_{0}, \mathrm{a}_{1}, \mathrm{a}_{2}\right)=\frac{9}{8} \mathrm{a}_{0}^{2}+\frac{5}{8} \mathrm{a}_{0} \mathrm{a}_{1}+\frac{1}{4} \mathrm{a}_{0} \mathrm{a}_{2}+\frac{5}{8} \mathrm{a}_{1}^{2}+\frac{17}{16} \mathrm{a}_{1} \mathrm{a}_{2}+\frac{77}{120} \mathrm{a}_{2}^{2},
$$

Now minimize of $J\left(a_{0}, a_{1}, a_{2}\right)$ subject to $x_{1}\left(t_{0}, a_{0}, a_{1}, a_{2}\right)=x_{0}$ leads to $a^{*}=\left(1,-\frac{412}{365}, \frac{54}{73}\right)$. In fact, $a^{*}$ is the value which minimize $J$, then $J\left(a^{*}\right)=0.8647260274$ is the solution of the optimal control problem (6)-(7) and substituting $\mathrm{a}^{*}$ into (8) and (9), we can calculate state and control variables approximately as:

$$
x_{1}(t)=\frac{54}{73} t^{2}-\frac{412}{365} t+1
$$

and

$$
u_{1}(t)=-\frac{27}{73} t^{2}+\frac{746}{365} t-\frac{1189}{730}
$$

The obtained solution and the analytical solution for the state and control variables and their errors are plotted in Figure 1 and Figure 2. Also, the optimal cost functional, J, obtained by the presented algorithm, is shown in Table 1. 

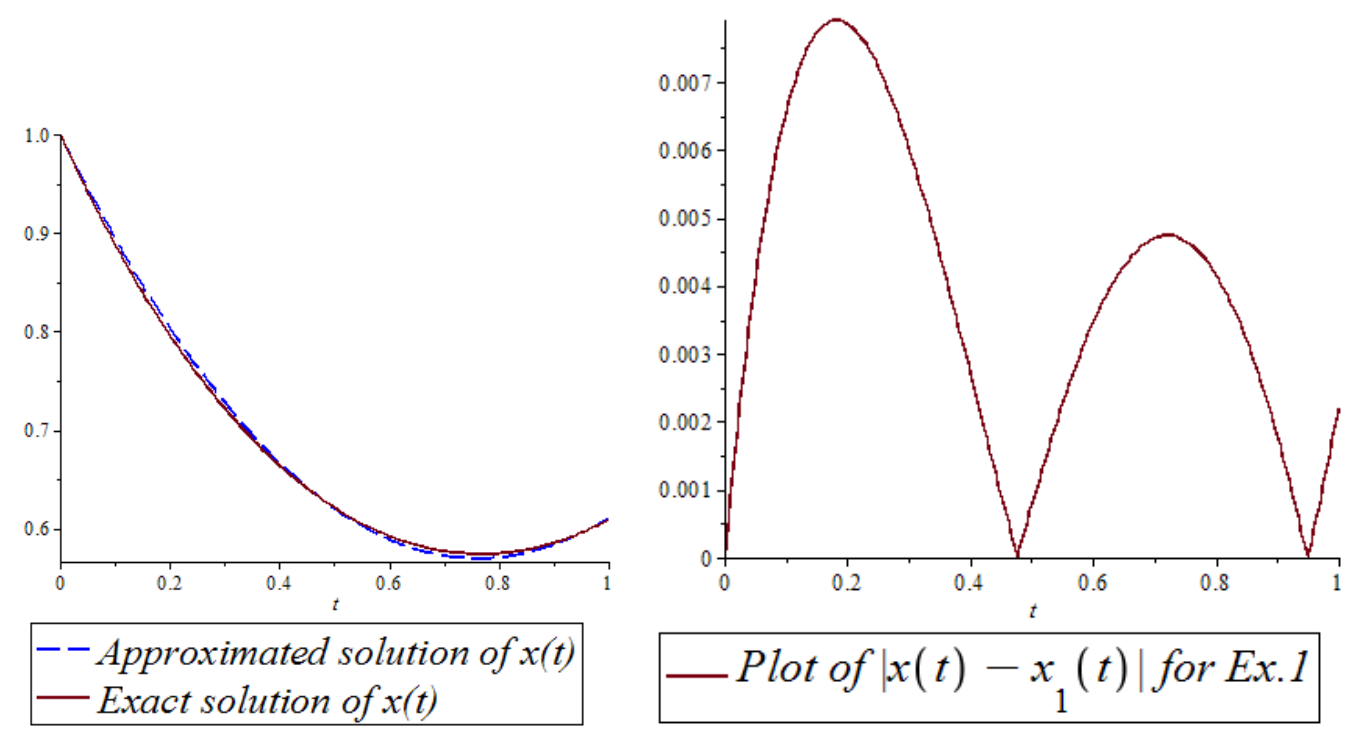

Fig 1. Graphs of approximate solutions of $\mathrm{x}(\mathrm{t})$ and its error for Example 1.
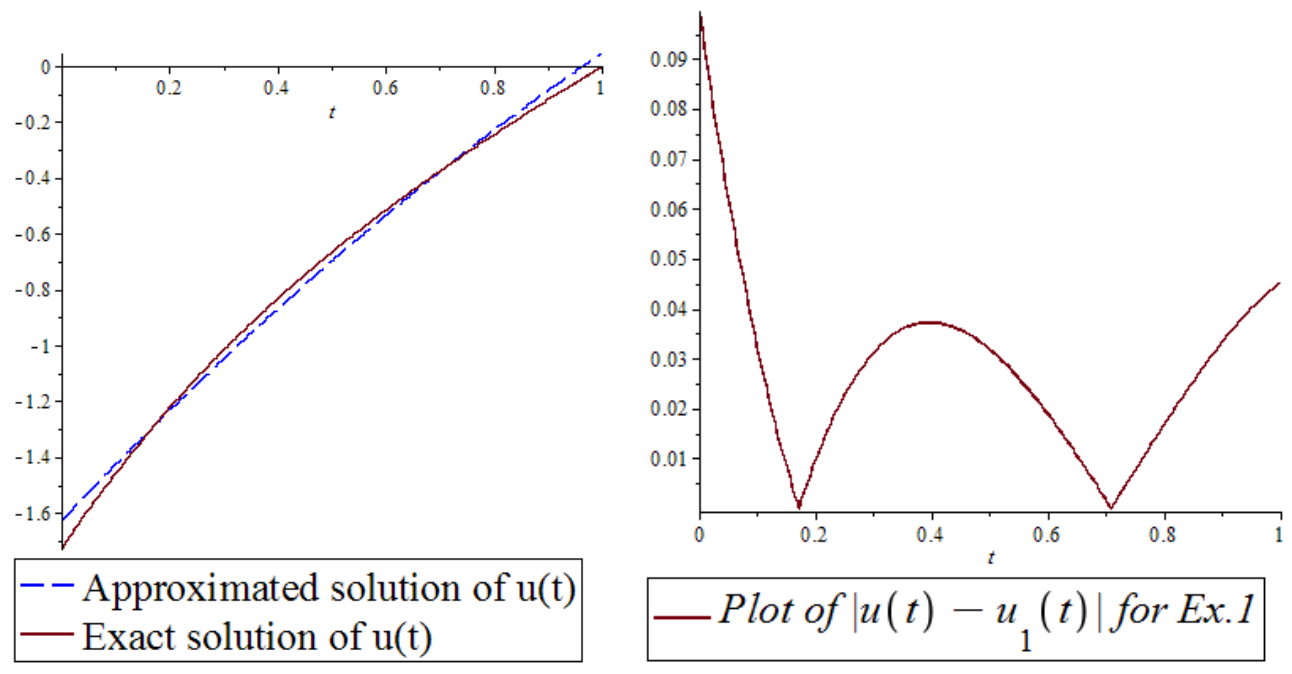

Fig 2. Graphs of approximate solutions of $\mathrm{u}(\mathrm{t})$ and its error for Example 1.

\begin{tabular}{|l|l|l|l|l|l|l|}
\hline \multirow{2}{*}{} & \multicolumn{2}{|l}{$\mathrm{m}=2$} & $\mathrm{~m}=3$ & $\mathrm{~m}=4$ & \\
\cline { 2 - 7 } & $\mathrm{J}$ & Error & $\mathrm{J}$ & Error & $\mathrm{J}$ & Error \\
\hline Step1 & 0.8647260274 & $5.7 \mathrm{E}-4$ & 0.8647260274 & $5.7 \mathrm{E}-4$ & 0.8647260274 & $5.7 \mathrm{E}-4$ \\
\hline \multirow{3}{*}{ Step2 } & 0.8645465237 & $3.9 \mathrm{E}-4$ & 0.8644940760 & $3.3 \mathrm{E}-4$ & 0.8643729445 & $2.1 \mathrm{E}-4$ \\
\cline { 2 - 7 } & 0.8645390704 & $3.8 \mathrm{E}-4$ & 0.8644557137 & $3.0 \mathrm{E}-4$ & 0.8643573922 & $2.0 \mathrm{E}-4$ \\
\cline { 2 - 7 } & 0.8645390446 & $3.7 \mathrm{E}-4$ & 0.8644550472 & $2.9 \mathrm{E}-4$ & 0.8643546452 & $1.9 \mathrm{E}-4$ \\
\hline
\end{tabular}

Table 1: The optimal cost functional J for Example 1 by using presented algorithm

Example2. Consider the following test problem:

Minimize:

$$
\int_{0}^{1}\left(\frac{1}{2} u^{2}(t)+\frac{1}{2} x(t) u(t)+\frac{5}{8} x^{2}(t)\right) d t
$$

Subject to:

$$
\dot{\mathrm{x}}(\mathrm{t})=\frac{1}{2} \mathrm{x}(\mathrm{t})+\mathrm{u}(\mathrm{t}), \quad \mathrm{x}(0)=1
$$


With the optimal solution:

$$
x^{*}(t)=\frac{\cosh (1-t)}{\cosh (1)}, u^{*}(t)=-\frac{(\tanh (1-t)+0.5) \cosh (1-t)}{\cosh (1)}
$$

Also, the exact solution for the performance index is:

$$
J=\frac{e^{6}+e^{3}-2}{e^{6}+4 e^{3}+4}=0.8641644978 .
$$

By using step (1) of the presented algorithm we consider this approximation of $\mathrm{x}_{1}(\mathrm{t})$ to start with:

$$
\mathrm{x}_{1}\left(\mathrm{t}, \mathrm{a}_{0}, \mathrm{a}_{1}, \mathrm{a}_{2}\right)=\sum_{\mathrm{i}=0}^{2} \mathrm{a}_{\mathrm{i}} \mathrm{t}^{\mathrm{i}}
$$

from equation (12), we have:

$$
\mathrm{u}_{1}\left(\mathrm{t}, \mathrm{a}_{0}, \mathrm{a}_{1}, \mathrm{a}_{2}\right)=-\frac{1}{2} \mathrm{a}_{2} \mathrm{t}^{2}+\left(2 \mathrm{a}_{2}-\frac{1}{2} \mathrm{a}_{1}\right) \mathrm{t}+\mathrm{a}_{1}-\frac{1}{2} \mathrm{a}_{0}
$$

then substituting equations (13) and (14) into equation (11) gives:

$$
J\left(a_{0}, a_{1}, a_{2}\right)=\frac{1}{2} a_{0}^{2}+\frac{1}{2} a_{0} a_{1}+\frac{1}{3} a_{0} a_{2}+\frac{2}{3} a_{1}^{2}+\frac{5}{4} a_{1} a_{2}+\frac{23}{30} a_{2}^{2},
$$

Now minimize of $\mathrm{J}\left(\mathrm{a}_{0}, \mathrm{a}_{1}, \mathrm{a}_{2}\right)$ subject to $\mathrm{x}_{1}\left(\mathrm{t}_{0}, \mathrm{a}_{0}, \mathrm{a}_{1}, \mathrm{a}_{2}\right)=\mathrm{x}_{0}$ leads to $\mathrm{a}^{*}=\left(1,-\frac{252}{347}, \frac{130}{347}\right)$. In fact, $\mathrm{a}^{*}$ is the value which minimize $J$, then $J\left(a^{*}\right)=0.3808837656$ is the solution of the optimal control problem (11)-(12) and substituting $\mathrm{a}^{*}$ into (13) and (14), we can calculate state and control variables approximately as:

$$
\mathrm{x}_{1}(\mathrm{t})=\frac{130}{347} \mathrm{t}^{2}-\frac{252}{347} \mathrm{t}+1
$$

and

$$
u_{1}(t)=-\frac{65}{347} t^{2}+\frac{386}{347} t-\frac{851}{694}
$$

The obtained solution and the analytical solution are plotted in Figure 3 and Figure 4. Also, the optimal cost functional, J, obtained by the presented algorithm, is shown in Table 2.

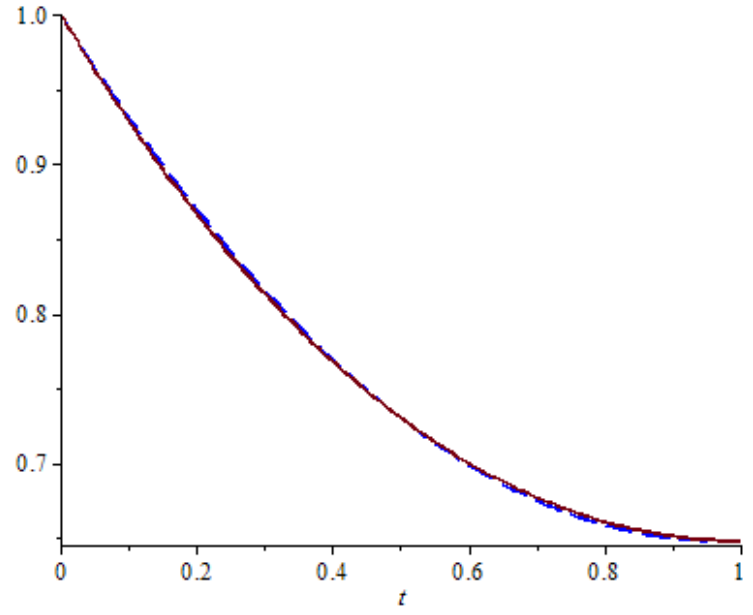

-- Approximated solution of $x(t)$ Exact solution of $x(t)$

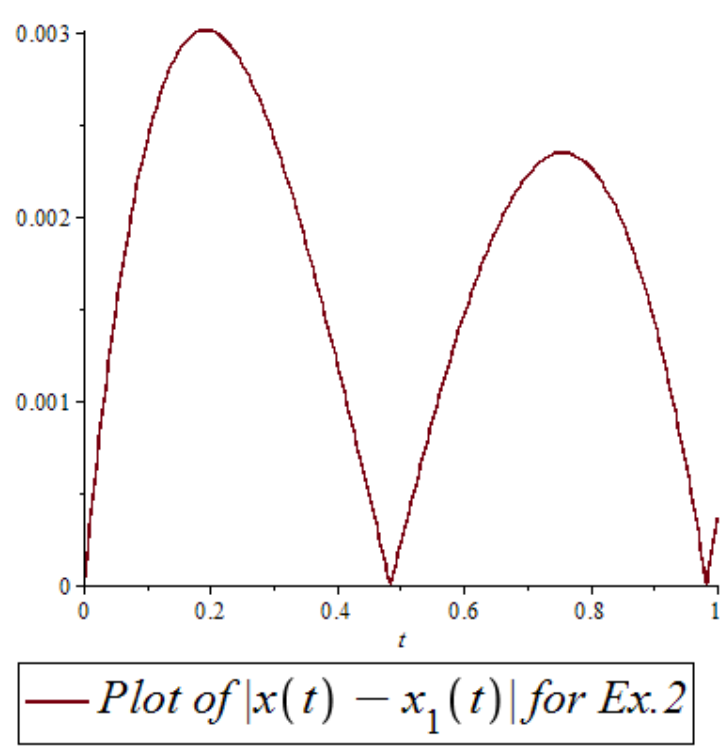

Fig 3. Graphs of approximate solutions of $x(t)$ and its error for Example 2. 

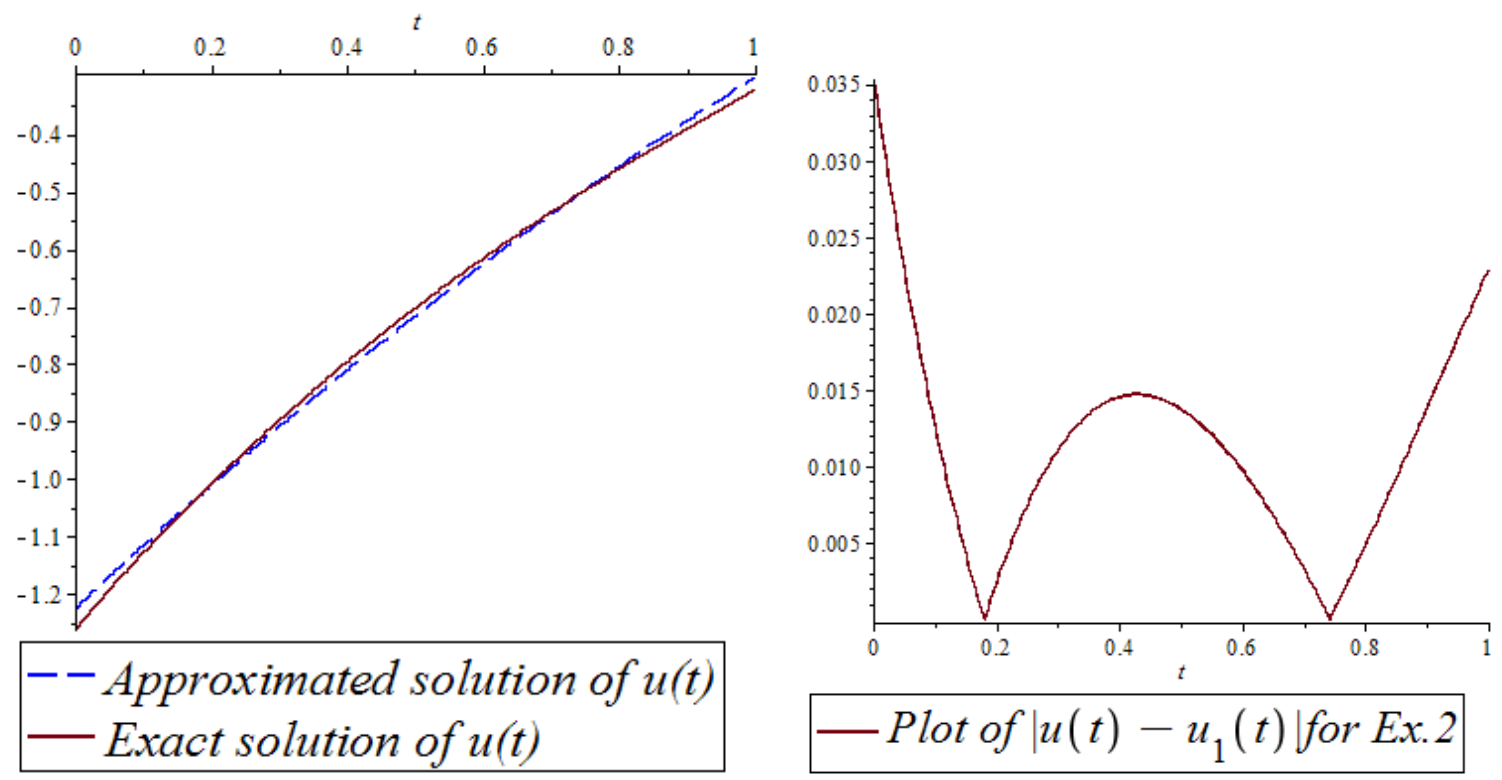

Plot of $\left|u(t)-u_{1}(t)\right|$ for Ex. 2

Fig 4. Graphs of approximate solutions of $u(t)$ and its error for Example 2.

\begin{tabular}{|c|c|c|c|c|c|c|}
\hline & \multicolumn{2}{|c|}{$\mathrm{m}=2$} & \multicolumn{2}{c|}{$\mathrm{m}=3$} & \multicolumn{2}{c|}{$\mathrm{m}=4$} \\
\cline { 2 - 7 } & $\mathrm{J}$ & Error & $\mathrm{J}$ & Error & $\mathrm{J}$ & Error \\
\hline Step1 & 0.3808837656 & $8.7 \mathrm{E}-5$ & 0.3808837656 & $8.7 \mathrm{E}-5$ & 0.3808837656 & $8.7 \mathrm{E}-5$ \\
\hline \multirow{2}{*}{ Step2 } & 0.3808377649 & $4.1 \mathrm{E}-5$ & 0.3808229011 & $2.6 \mathrm{E}-5$ & 0.3808148489 & $1.8 \mathrm{E}-5$ \\
\cline { 2 - 7 } & 0.3808330111 & $3.6 \mathrm{E}-5$ & 0.3808197723 & $2.3 \mathrm{E}-5$ & 0.3808137562 & $1.7 \mathrm{E}-5$ \\
\hline
\end{tabular}

Table 2: The optimal cost functional J for Example 1 by using presented algorithm

\section{Van der Pol oscillator}

In this section, we consider the Van der Pol oscillator problem. The system state equations are:

$$
\begin{aligned}
& \dot{\mathrm{x}}_{1}(\mathrm{t})=\mathrm{x}_{2}(\mathrm{t}), \\
& \mathrm{u}(\mathrm{t})=\dot{\mathrm{x}}_{2}(\mathrm{t})+\mathrm{x}_{1}(\mathrm{t})+\left(\mathrm{x}_{1}^{2}(\mathrm{t})-1\right) \mathrm{x}_{2}(\mathrm{t}),
\end{aligned}
$$

The cost function to be minimized, starting from the initial states $\mathrm{x}_{1}(0)=1$ and $\mathrm{x}_{2}(0)=0$, is:

$$
\mathrm{J}=\frac{1}{2} \int_{0}^{5}\left(\mathrm{u}^{2}+\mathrm{x}_{1}{ }^{2}+\mathrm{x}_{2}{ }^{2}\right) \mathrm{dt}
$$

in addition, the system is subject to the following terminal state constraints:

$$
\begin{aligned}
& x_{1}(5)=-1, \\
& x_{2}(5)=0,
\end{aligned}
$$

In the following, we performance the solution of the problem by using presented algorithm. So we consider this approximation of $x_{1}(t)$ to start with:

$$
\mathrm{x}_{1}\left(\mathrm{t}, \mathrm{a}_{0}, \ldots, \mathrm{a}_{4}\right)=\sum_{\mathrm{i}=0}^{4} \mathrm{a}_{\mathrm{i}} \mathrm{t}^{\mathrm{i}}
$$

by using equation (16) we have $\mathrm{x}_{2}\left(\mathrm{t}, \mathrm{a}_{0}, \ldots, \mathrm{a}_{4}\right)$ and then $\mathrm{u}\left(\mathrm{t}, \mathrm{a}_{0}, \ldots, \mathrm{a}_{4}\right)$ is obtained from equation (17). Now we obtain $J$ as a function of $\left(a_{0}, \ldots, a_{4}\right)$ by using equation (18) and denote it by $J\left(a_{0}, \ldots, a_{4}\right)$ and solve above optimization problem. In fact, The new problem is to minimization problem subject to the equality constraint: 


$$
\begin{aligned}
& \min _{\left(\mathrm{a}_{0}, \ldots, \mathrm{a}_{4}\right) \in \mathbb{R}^{5}} \mathrm{~J}\left(\mathrm{a}_{0}, \ldots, \mathrm{a}_{4}\right), \\
& \text { s.t. } \\
& \mathrm{x}_{1}\left(0, \mathrm{a}_{0}, \ldots, \mathrm{a}_{4}\right)=0 \\
& \mathrm{x}_{2}\left(0, \mathrm{a}_{0}, \ldots, \mathrm{a}_{4}\right)=0 \\
& \mathrm{x}_{1}\left(5, \mathrm{a}_{0}, \ldots, \mathrm{a}_{4}\right)=-1, \\
& \mathrm{x}_{2}\left(5, \mathrm{a}_{0}, \ldots, \mathrm{a}_{4}\right)=0,
\end{aligned}
$$

The dynamic optimal control problem is approximated by a quadratic programming problem. The optimal value of the vector $\mathrm{a}^{*}$ can be obtained from the standard quadratic programming method as:

$$
\left(\mathrm{a}_{0}, \mathrm{a}_{1}, \mathrm{a}_{2}, \mathrm{a}_{3}, \mathrm{a}_{4}\right)=(1,0,-0.2166400646,0.02265602582,0.0009343974175)
$$

In fact, $\mathrm{a}^{*}$ is the value which minimizes $\mathrm{J}$ and $\mathrm{J}\left(\mathrm{a}^{*}\right)=2.43380762$ is the solution of optimal control problem (19)(19). By using $\mathrm{a}^{*}$, we can calculate state approximately as:

$$
\mathrm{x}_{1}(\mathrm{t})=9.34397 \times 10^{-4} \mathrm{t}^{4}+2.265603 \times 10^{-2} \mathrm{t}^{3}-0.216640 \mathrm{t}+1
$$

The solution obtained is plotted in Figure 3 . In fact, state and control variables $\mathrm{x}_{1}(\mathrm{t}), \mathrm{x}_{2}(\mathrm{t})$ and $\mathrm{u}(\mathrm{t})$ are plotted for $\mathrm{n}=1$ and $\mathrm{n}=2$ in Figure 5 .
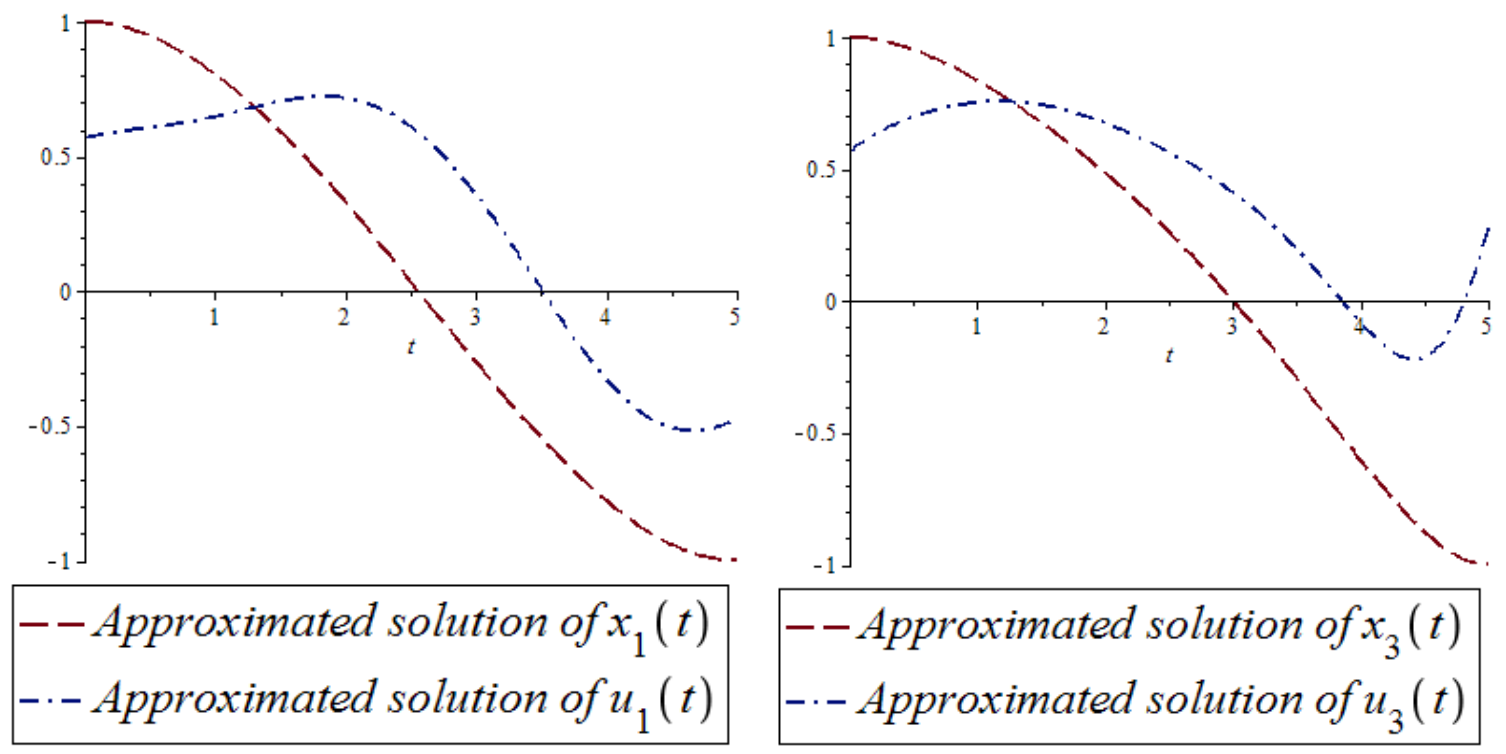

Fig 5. Solution of the Van der Pol oscillator problem.

The approximate solution for the performance index as given in [20] is J $=2.1439039$ the optimal cost functionalJ, obtained by presented algorithm, is shown in Table 3.

Table 3. The optimal cost functional $J$ for the Van der Pol oscillator problem.

\section{CONCLUSION}

\begin{tabular}{|c|c|c|}
\hline iteration & Present method & error \\
\hline 1 & 2.153139564 & $0.9 \mathrm{E}-2$ \\
\hline 2 & 2.144127466 & $0.2 \mathrm{E}-3$ \\
\hline 3 & 2.143904324 & $2.1 \mathrm{E}-6$ \\
\hline
\end{tabular}

In this paper, a simple computational algorithm for minimizing performance index was obtained by using state parameterization method, which can easily be applied to complex problems as well. One of the advantages of this method is using a computational algorithm with a fast convergence. This algorithm can be used to approximate the control and state variables as a function of time. The suggested algorithm was then applied to Van der Pol oscillator problem problem. The results obtained demonstrate the reliability and efficiency of the proposed algorithm. 


\section{References}

[1] L. S. Pontryagin, V. G. Boltyanskii, R. V. Gamkrelidze, "The mathematical theory of optimal processes", (1962).

[2] R. Bellman, "Dynamic Programming”, University Press, Princeton, N J, (1957).

[3] W. H. Fleming, C. J. Rishel, "Deterministic and Stochastic Optimal Control", Springer-Verlag, (1975).

[4] W. H. Fleming, H. M. Soner, "Controlled Markov Processes and Viscosity Solutions", Springer, (2006).

[5] D. E. Kirk, “Optimal Control Theory An Introduction”, Prentice-Hall, Englewood Cliffs, (1970).

[6] A. B.Pantelev, A. C. Bortakovski, T. A. Letova, "Some Issues and Examples in Optimal Control", MAI Press, Moscow (in Russian), 1996.

[7] H.J. Kushner, P.G. Dupuis, "Numerical Methods for Stochastic Control Problems in Continuous Time", $2^{\text {nd }}$ Edition, Springer-Verlag, New York, NY, (2001).

[8] H.J. Kushner, "A partial history of the early development of continuous-time nonlinear stochastic systems theory", Automatica 50.2 (2014): 303-334.

[9] A. Jajarmi, N. Pariz, S. Effati, A. V. Kamyad, "Infinite horizon optimal control for nonlinear interconnected Large-Scale dynamical systems with an application to optimal attitude control", Asian. J. Control. 15 (2013) 1-12.

[10] B. Kafash, A. Delavarkhalafi, S. M. Karbassi, "Application of variational iteration method for Hamilton-Jacobi-Bellman equations", Appl. Math. Modell. 37 (2013) 3917-3928.

[11] H. M. Jaddu, "Direct solution of nonlinear optimal control problems using quasilinearization and Chebyshev polynomials", J. Franklin Inst. 339 (2002) 479-498.

[12] K. Maleknejad, H. Almasieh, "Optimal control of Volterra integral equations via triangular functions", Math. Comput. Modell. 53 (2011) 1902-1909.

[13] E. Hesameddini, A. Fakharzadeh Jahromi, M. Soleimanivareki, H. Alimorad, "Differential transformation method for solving a class of nonlinear optimal control problems", The Journal of Mathematics and Computer Science Vol .5 No.1 (2012) 67-74.

[14] H. M. Jaddu, "Numerical Methods for solving optimal control problems using chebyshev polynomials", $\mathrm{PhD}$ thesis, School of Information Science, Japan Advanced Institute of Science and Technology, (1998).

[15] B. Kafash, A. Delavarkhalafi, S. M. Karbassi, "Application of Chebyshev polynomials to derive efficient algorithms for the solution of optimal control problems", Sci. Iran. 19 (2012) 795-805.

[16] T. Akman, K. Bülent, "Variational time discretization methods for optimal control problems governed by diffusion-convection-reaction equations", Journal of Computational and Applied Mathematics 272 (2014): 41-56.

[17] Liu, Chongyang, Ryan Loxton, Kok Lay Teo, “A computational method for solving time-delay optimal control problems with free terminal time", Systems \& Control Letters 72 (2014): 53-60.

[18] P. Chris, et al., "Consistent approximation of a nonlinear optimal control problem with uncertain parameters", Automatica (2014).

[19] H. Sadeghian, et al., "On the linear-quadratic regulator problem in one-dimensional linear fractional stochastic systems", Automatica 50.1 (2014): 282-286.

[20] E. Tohidi, H. Saberi Nik, "A Bessel collocation method for solving fractional optimal control problems", Applied Mathematical Modelling (2014).

[21] B. D. Craven, "Control and Optimization", Chapman \& Hall, London (1995).

[22] K.L. Teo, L. S. Jennings, H.W.J. Lee, V. Rehbock, "The control parametrization enhancing transform for constrained optimal control problems", J. Austral. Math. Soc. Ser. B., 40 (1999), pp. 314-335.

[23] H. W. J. Lee, K. L. Teo, L.S. Jennings, H. W. J. Lee, V. Rehbock, “Control parametrization enhancing technique for time optimal control problem", Dynamical Syst. Appl., 6 (1977), pp. 243-261. 
[24] J. Vlassenbroeck, “A chebyshev polynomial method for optimal control with state constraints", Automatica. 24(4) (1988), pp. 499-506.

[25] R. Van Dooren, J. Vlassenbroeck, "Chebyshev series solution of the controlled Duffing oscillator", J. Comput. Phys., 47 (1982), 321-329.

[26] S. E. El-Gendi, "Chebyshev solution of differential, integral, and integro-differential equations", Comput. J., 12 (1969), 282-287.

[27] T. M. El-Gindy, H. M. El-Hawary, M. S. Salim, M. El-Kady, "A Chebyshev approximation for solving opimal control problems", Comput. Math. Appl., 29(1995), 35-45.

[28] M. El-Kady, Elsayed M.E. Elbarbary., "A Chebyshev expansion method for solving nonlinear optimal control problems", Applied Mathematics and Computation, 129 (2002), 171-182.

[29] H.H. Mehne, A. Hashemi Borzabadi, "A numerical method for solving optimal control problems using state parametrization", Numer Algor., 42 (2006), pp. 165-169.

[30] P.A. Frick, D.J. Stech, "Solution of optimal control problems on a parallel machine using the Epsilon method", Optim. Control Appl. Methods., 16(1995) 1-17.

[31] B. Kafash, A. Delavarkhalafi, S. M. Karbassi, "Numerical Solution of Nonlinear Optimal Control Problems Based on State Parametrization", Iranian Journal of Science and Technology, 35 (A3) (2012) 331-340.

[32] B. Kafash, A. Delavarkhalafi, S. M. Karbassi, K. Boubaker, "A Numerical Approach for Solving Optimal Control Problems Using the Boubaker Polynomials Expansion Scheme", Journal of Interpolation and Approximation in Scientific Computing 2014 (2014) 1-18. 